\title{
INSTRUÇÃO E ARTE NA ESCOLA PRIMÁRIA DO PARANÁ NO OITOCENTOS: PROPOSIÇÕES E EFETIVAÇÕES (1870-1880)
}

Etienne Baldez Louzada Barbosa

UFPR

\section{RESUMO}

O Paraná surge como província, oficialmente, em dezembro de 1853 e, desde então, reorganizou a estrutura administrativa, incluindo nessa a instrução pública primária, que ficou sob responsabilidade da inspeção do ensino. O foco se volta para os sujeitos que estavam no topo da direção da instrução - inspetores/diretores e presidentes da província com o intuito de identificar, nos relatos por eles deixados, o que era proposto para o ensino de arte nas escolas públicas primárias. A historiografia que se volta para tal ensino no século XIX tem demonstrado que este era entendido como o ensino de desenho geométrico. No Paraná tal perspectiva pode também ser confirmada com a circulação de compêndios didáticos de desenho geométrico, como o de Abílio César Borges. Todavia, a hipótese aqui traçada é a de que havia proposições para o ensino artístico, para além do desenho geométrico. As fontes que permitem tal procedimento são revistas periódicas, jornais e os relatórios dos inspetores/diretores gerais de instrução pública, disponibilizados no acervo da Biblioteca Nacional (RJ), no Museu Paranaense (PR) e no Arquivo Público do Paraná.

Palavras-chave: instrução pública primária; ensino de arte; inspeção do ensino; Paraná.

\section{EDUCATION AND ART IN THE PRIMARY SCHOOL OF PARANÁ IN THE EIGHT HUNDRED: PROPOSITIONS AND EFETIVATIONS (1870-1880)}

\begin{abstract}
Paraná emerges as province, officially, in December 1853 and has since reorganized the administrative structure, including in this the primary public education, which was under the responsability of the inspection of education. The focus turns to the individuals who were on top of the direction of education - inspectors/directors and presidents of the province - in order to identify, in the reports left by them, what was proposed for the teaching of art in public primary schools. The historiography that turns to the education in the nineteenth century has shown that this was understood as the teaching of geometric drawing. In Paraná this perspective can also be confirmed with the movement of educational compendia of geometric drawing, such as Abílio César Borges's compendium. However, the assumption here outlined is that there were propositions for art teaching, in addition to the geometric drawing. Sources that allow such procedure are periodicals, newspapers and the reports from the general inspectors/directors of public instruction, available at the National Library (RJ), the Paranaense Museum (PR) and the Public Archives of Paraná.
\end{abstract}

Keywords: primary public education; art teaching; inspection of education; Paraná. 
O que ensinam as nossas escolas primárias? Questão esta, que não perde a base da inquietação que assola os partícipes do ensino independente do tempo e lugar, foi formulada, em 1871, pelo inspetor geral Bento Fernandes de Barros ${ }^{1}$. Ele esboça a resposta e aponta que na escola se ensina a leitura, a caligrafia, o cálculo e algumas fracas noções de gramática e de doutrina cristã, mas reforça que esse limitado ensino não instrui, não eleva, não moraliza, não satisfaz o fim que se deve atingir - a educação (BARROS, 1871, p.04). Passado mais de um século, a questão não se perde, porém, a ela se acrescentam outras inquietações, tais como: o que mais os partícipes do ensino apontavam como necessário ser ensinado nas escolas públicas primárias paranaenses? O presente trabalho foca nessa questão como ponto de partida, analisando os relatórios de inspetores gerais, as correspondências de governo trocadas pela Inspetoria de Instrução Pública da província do Paraná e periódicos da época. A hipótese aqui esboçada é a de que havia algumas proposições sobre o ensino artístico para as escolas públicas primárias paranaenses, feitas pelos responsáveis pelo ensino.

Ana Mae Barbosa (1978) demarca que as "referências que se encontram sobre Arte na escola e seu ensino são pouco frequentes, esparsas e excessivamente gerais" (BARBOSA, 1978, p.13). Passadas algumas décadas desde a publicação do seu trabalho, podemos perceber que muitas pesquisas têm tomado o ensino artístico na escola, contudo, ainda há espaço para se refletir e buscar indícios de tal prática no século XIX, no Paraná. Dulce Osinski (2002) demonstra que o Oitocentos foi marcado por profundas mudanças na ordem tecnológica, econômica, social e política - e que isto contribuiu para as transformações também no ensino de arte, que, paulatinamente, agregou o ideal de preparar o homem para a utilização da máquina e seguir os rumos do progresso industrial, com os conteúdos ministrados em sala de aula. E o método escolhido envolveu "conteúdos rígidos que privilegiavam o ensino do desenho, muitas vezes geométrico, onde a técnica e a cópia imitativa eram as estratégias mais frequentes utilizadas para transmitir os conhecimentos" (OSINSKI, 2002, p.53).

A preocupação com ensino artístico no Brasil, no início do século XIX, foi prioritariamente com o ensino superior. Em 1816, D. João VI criou o ensino artístico por meio de decreto, com a fundação da Escola de Ciências, Artes e Ofícios, no Rio de Janeiro, o que contribuiu para a institucionalização da categoria artista, que mesmo com a vinda da Missão Francesa, "não desfrutava a mesma importância social atribuída ao escritor, ao poeta" (BARBOSA, 1978, p.21). Havia uma distinção entre a arte (pintura e desenho) como adorno e a arte como aplicação à indústria. NikolausPevsner (2005) evidencia a ocorrência progressiva, ao longo do século XIX, em diversos países, do ensino de arte nas academias existentes e não em cursos elementares, o que contribuiu para que estas academias fossem elevadas à categoria de Universidades ou Colégios de Arte. Em contraposição, "os rudimentos do desenho passaram a ser ensinados nas escolas primárias e secundárias, deslocando-se o desenho industrial para as escolas técnicas, os cursos profissionalizantes ou as escolas municipais de arte" (PEVSNER, 2005, p.288).

Como aponta Ana Mae Barbosa (1978), o Brasil também tentou seguir esta tendência e, no que concerne ao desenho, "foram criados cursos de Desenho Técnico em 1818, no Rio de Janeiro, e em 1817, em Vila Rica e na Bahia, que não tiveram grande sucesso" (BARBOSA, 1978, p.25). No Paraná, podemos observar nos documentos relativos à instrução pública, durante a década de 1870, a recorrência em utilizar compêndios de desenho linear ou geométrico nas escolas primárias, principalmente o livro 
de Abílio César Borges ${ }^{2}$. Verificando esta primeira prática do ensino de desenho na província, o escopo se volta para identificar o que os inspetores/diretores gerais ${ }^{3}$ propuseram como pertinente ser trabalhado nas escolas públicas primárias paranaenses. Assim, o trabalho se subdivide em dois momentos. No primeiro, o foco se volta para análise da introdução de um dos livros de Abílio César Borges, que circulou no Paraná na década de 1880, intitulado: Desenho Linear ou Elementos de Geometria Popular ${ }^{4}$. Recorre-se a esta obra em especial, publicada na década de 1870 e reproduzida até a década de 1940, com o objetivo de ampliar os estudos que tomam o presente livro como fonte para compreender o ensino artístico pelo viés da história da educação no Brasil, na segunda metade do Oitocentos. No segundo momento, o olhar se volta para o relatório do inspetor geral João Manoel da Cunha ${ }^{5}$, elaborado em 1875. Neste o inspetor pincela sua proposta para o ensino na província.

\section{"O desenho linear é o ABC do belo"}

Como mencionado, o ensino de desenho na educação era concebido como uma importante base para a preparação de mão-de-obra para a indústria. David Thistlewood (1986) demarca que a educação de arte e design na Inglaterra passa por uma reformulação pelos legisladores no século XIX, que tinham em mente o desenho como disciplina e que a isso se aliaram as necessidades da indústria Vitoriana, surgindo, então, desenho como "instrução manual" e também "coordenação de olho e mão". O autor pontua que "foi também isto, no princípio da arte-educação em geral, que estabeleceu o princípio que todos os movimentos reformistas seguiram, para justificar as mudanças em nome da utilidade social" (THISTLEWOOD, 1986, p.37). Ana Mae Barbosa (1984) sustenta que a preocupação com o ensino de arte no Brasil, em específico com o desenho geométrico, teve início concomitantemente com o surto de industrialização ocorrido no final do século XIX e que Abílio César Borges "foi o responsável pela implantação dos métodos de Walter Smith, que se tornaram a base para o ensino de desenho na escola primária e secundária no Brasil por quase trinta anos" (BARBOSA, 1984, p.13).

Os livros de Leitura de Abílio já tinham ampla circulação na província do Paraná, muitos deles sendo doações do autor para a escola pública primária. Quando Abílio elabora o livro Desenho Linear ou Elementos de Geometria Prática Popular, este também é enviado para as escolas paranaenses. Para ser aprovado, o livro passava pelo inspetor/diretor geral - grande mentor quanto à escolha, compra e distribuição de livros didáticos na província - e, a partir de 1876, pelo Conselho Literário, que passou a abarcar tal função. Não havia uma legislação que regulasse tal escolha, com critérios a serem observados ao selecionar um livro. Esta seleção passava pela análise de uma comissão formada por integrantes do Conselho Literário, que ao final emitia o parecer, ou, em alguns casos, aos professores eram distribuídos livros para serem testados em sala de aula e depois reportada sua aplicabilidade à Inspetoria de Instrução Pública.

Ente 1879 e 1882 o Conselho Literário recebeu dez solicitações referentes a novos livros didáticos para serem adotados nas escolas primárias paranaenses. Destas, ele negou quatro. A base para tal negativa era a já utilização dos livros de Abílio César Borges na província ${ }^{6}$.Os "livros de Abílio" - como eram mencionados em alguns documentos - eram aprovados pelo conteúdo e de acordo com o que era melhor para o governo, para os cofres públicos:

Acuse ainda que, atendendo-se à que o Dr. Abílio por mais de uma vez e por pura espontaneidade filantrópica ofereceu mais de sete mil volumes de seus $1^{\circ}, 2^{\circ}$ e $3^{\circ}$ livros de leitura, com os quais têm sido provido as 
escolas, o Conselho pensa que é mais razoável, quando o permitirem os cofres, oficiar-se aquele préstimo (ilegível) a fim de se obter para compra os seus livros, que são os que têm conseguido bons resultados em todo o Império. (LIVRO 87, 01/09/1879).

A parceria com o Dr. Abílio, que já vinha acontecendo há alguns anos, era mais vantajosa para os cofres provinciais e, naquele momento, o Conselho Literário mostrou-se fiel a essa condição, indicando que quando houvesse verba, comprariam, sim, mais livros, só que do Dr. Abílio. As relações em torno da solicitação, aquisição e distribuição de uma obra na estrutura de ensino paranaense eram muito mais complexas do que ser este ou aquele livro/autor bom ou ruim, ou de ser lucrativo ou não para o governo provincial, pois também eram nuançadas por acordos políticos e pessoais. Todavia, escolher o livro Desenho Linear ou Elementos de Geometria Prática Popular era também ir de encontro com as ideias e métodos que circulavam em outras províncias e países, como veremos em seguida.

Abílio Cesar Borges escreve de um lugar social ${ }^{7}$ conquistado e a ele conferido. A contracapa já nos informa muito desse lugar, por elencar uma série de funções do referido autor. Um rápido olhar já nos diz que é uma pessoa que tem uma profunda inserção nos assuntos referentes à instrução. $\mathrm{O}$ prólogo confirma isto, quando o autor escreve que atendeu às observações feitas pelos inspetores, professores e colegas educadores para reformular seu compêndio. É o reforço de que o livro já circulou por quem entende do assunto, seja na teoria (inspetores e colegas educadores) seja na prática (professores). Este reforço é ainda maior quando se insere no referido texto, as cartas que abonam a utilização do livro nas escolas públicas primárias, como as de André Rebouças e José Menezes.

O foco da análise se desloca para este livro, em especial, pela sua proposta de arte na educação, entendida como o ensino de desenho geométrico durante a segunda metade do século XIX. O autor se posiciona, na introdução, como uma pessoa que tem experiência sobre o tema. Ele evidencia que já fazia pesquisas sobre o assunto há 20 anos; que quando foi diretor geral na Bahia trabalhou para que o ensino de desenho linear ou geométrico fosse ofertado pelos professores em todas as escolas públicas; tanto no GymnasioBahiano quanto no CollegioAbilio tratou o desenho geométrico como fundamental para a instrução primária. Enfim, ele traz sua experiência para mostrar que escreve sobre um assunto que pesquisou e que colocou em prática, com sucesso. Ana Mae Barbosa (1978) cotejou o trabalho de Walter Smith, muito citado na introdução, com o que Abílio construiu como método em seu livro e observa que há uma semelhança evidente entre os dois, como a autora reforça: "embora seja apresentado como um método próprio do autor, foi retirado dos princípios metodológicos de Walter Smith" (BARBOSA, 1978, p. 55).

O segundo esforço do autor em mostrar que sua obra tem um diferencial das outras é revelar o que circulava sobre o desenho geométrico no período. Ele cita as "nações civilizadas", grandes e pequenas, que se empenham em propagar esta prática; os países "em que mais adiantada vai a instrução popular" que adotam o desenho geométrico em todos os níveis; sujeitos e autores conhecidos que já colocaram a importância do desenho geométrico ser ofertado nas escolas em pauta(BORGES, 1882, p.09). Ele faz este movimento para referendar o que escreve, mostrando que não é o primeiro a pensar sobre a pertinência do ensino de desenho e que o assunto está em pauta entre os "sujeitos civilizados". Se seguirmos os rastros ${ }^{8}$ da discussão sobre o ensino de desenho nos periódicos que circularam na época, encontraremos muitos artigos e notícias sobre o ensino em outros países. A própria carta que André Rebouças escreve a Abílio sobre o livro, em janeiro de 1879, foi publicada no jornal O Novo Mundo ${ }^{9}$ - PeriódicoIllustrado do Progresso da Edade - em junho do mesmo ano (O NOVO MUNDO, 1879, p. 138). Se 
atendo a este periódico, onde foi publicada a carta, verificamos que durante a década de 1870 houve um reforço intenso da importância do desenho geométrico e exemplos de como os outros países estavam se organizando para administrar este ensino, como nos Institutos Agrícolas (onde se ensinava, durante quatro anos, aritmética comercial, arte de guarda-livros, álgebra, geometria, trigonometria, agrimensura, construção de estradas e pontes), em Massachusets, lugar este "que é tão célebre por suas instituições literárias e industriais" (O NOVO MUNDO, 1870, p. 11).

Um terceiro movimento que Abílio realiza ao escrever é demarcar o que pensa sobre o desenho geométrico. Segundo o autor, era uma disciplina ${ }^{10}$ que deveria fazer parte da instrução pública primária, não somente da secundária e superior ${ }^{11}$;"“fácil de ensinar e de aprender, é de incontestável necessidade para os progressos gerais de um povo"; e que, pensando no ensino, "pode e deve começar ao mesmo tempo que o da escrita" (BORGES, 1882, p.09); que também trabalha a grafia, visto que "o desenho é uma escrita não abstrata" (Ibidem, p.10); deve ser uma "cópia inteligente, que leva pouco a pouco o discípulo a exprimir suas próprias ideias" (Idem, p.11); o "desenho geométrico é tão indispensável ao engenheiro e ao arquiteto como ao artista e ao operário; e é útil, pelo menos, ao homem do mundo, que não quer ser completamente estranho ao desenvolvimento industrial de seu tempo"; que "chega ao espírito falando aos olhos" (Ibidem, p.12) e, por último, que o desenho geométrico deve ser ensinado a todos pelos professores "ordinários", ou seja, não necessariamente formados para tal função (Ibidem, p.14). Circe Bittencourt (1993) mostra que, no decorrer do século XIX, o livro utilizado nas aulas se destinava mais ao professor, no sentido que este se assegurava do domínio dos conteúdos a serem transmitidos para depois ser considerado um material também para o aluno (BITTENCOURT, 1993, p.25-26). Antônio Batista (1999) corrobora essa interpretação e aponta os impressos e livros didáticos como "instrumentos de formação" também para o professor, não somente para o aluno (BATISTA, 1999, p.551).

O pesquisador norte americano Elliot Eisner elencou sete visões de arte-educação que perpassam os estudos que se propõem a discutir arte na e para a escola. São elas: autoexpressão criadora; solução criadora de problemas; desenvolvimento cognitivo; cultura visual; ser disciplina; potencializar a performance acadêmica; preparação para o trabalho (BARBOSA, 2006, p.56). Pelo que Abílio escreve, podemos dizer que sua visão se enquadra perfeitamente em pelo menos duas dessas: a da arte (desenho geométrico) como disciplina e como preparação para o trabalho. Segundo Ana Mae Barbosa (2006) "encontramos na história do ensino da Arte no Brasil a configuração da arte como preparação para o trabalho, no fim do século XIX, ancorada nas ideias liberais de Rui Barbosa, André Rebouças e Abílio César Borges" (BARBOSA, 2006, p.57). Na carta de André Rebouças para Abílio vemos que este considera o desenho linear como o "ABC do belo" (BORGES, 1882, p.20) e importante para a educação para o trabalho ("necessitamos educar esta nação para o trabalho (...) necessitamos restituir a ciência positiva, a agricultura e à indústria os talentos que se esterilizavam nas egoísticas lutas que denominavam política") e para a indústria ("seu livrinho será um grande guia da infância para as províncias da indústria e do trabalho em geral") (Ibidem, p.22). Ligar o desenho ao belo já era uma expressão utilizada por André Rebouças, como podemos notar no texto publicado anteriormente: "o desenho é a escola primeira do belo. O justo, o bom e o belo formam uma trindade sublime" (O NOVO MUNDO, 1878, p.246). Observa-se uma tendência nas fontes de otimizar o ensino de desenho objetivando também, a conscientização de preceitos éticos e morais, tal como identificou Barbosa (1978) como o efeito moral da Arte (BARBOSA, 1978, p.61). 
Mas não era somente o livro Desenho Linear ou Elementos de Geometria Prática Popular o escolhido pela inspetoria para compor o acervo da instrução pública primária na província. O Dr. Abílio também enviou outro compêndio, durante o mesmo período, como informou o secretário da presidência ao diretor geral Euclides Francisco de Moura: "remete 1970 exemplares da aritmética composta por Manoel O. Rodrigues da Costa, oferecidos pelo Dr. Abílio César Borges para serem distribuídos para as escolas primárias" (O DEZENOVE DE DEZEMBRO, 1879, p. 03). Avançando alguns anos, em 1882, o livro Curso de Desenho Linear, de Paulino Martins Pacheco ${ }^{12}$, foi submetido a uma comissão de avaliação indicada pelo Conselho Literário que emitiu o seguinte parecer: “(...) entende que dita obra presta-se perfeitamente ao ensino desta matéria", ou seja, o do Abílio não era o único livro com conteúdo aprovado,"porém que, havendo em igualdade de circunstâncias o compêndio do Dr. Abílio serve bem para a província; não há necessidade de se fazer a aquisição dele"(LIVRO 88, 03/10/1882 - grifos meus). O livro servia bempara a província não somente pelo conteúdo condizente com o que se esperava do ensino de desenho geométrico da época, mas também pelas facilidades - Abílio estava sempre enviando exemplares gratuitos ${ }^{13}$ - e pela manutenção de uma relação de troca e de fidelidade, pois quando fosse necessário comprar um livro, se daria prioridade para os de Abílio, pela parceria que este já mantinha.

\section{O homem e o aluno no século XIX}

Ainda no periódico O Novo Mundo, de onde pudemos observar a circulação de ideias sobre o ensino do desenho, encontramos a seguinte descrição:

O homem do século dezenove é um trabalhador ou 'operário': é aquele ser nobilitado pela pena divina de 'comer o seu pão com o suor do seu rosto'. Entretanto, nas horas de descanso, ele alimenta a sua alma com a investigação da verdade e da justiça, orientando-se das evoluções do dia em toda parte do mundo; em outras palavras, ele fortifica a sua consciência de Homem e de rei da terra inteira, informando-se da causa geral da humanidade. Tal é o único homem digno deste nome, e do respeito de seus semelhantes, nesta idade de cristianismo e razão. $(\mathrm{O}$ NOVO MUNDO, 1871, p. 02).

O texto acima pode ser entendido como uma representação do homem no Oitocentos, segundo o periódico, tomando como base um dos significados atribuídos por Roger Chartier a esse conceito, como um conjunto de "representações coletivas que incorporam nos indivíduos as divisões do mundo social e estruturam os esquemas de percepção e apreciação a partir dos quais estes classificam, julgam e agem" (CHARTIER, 1994, p.104). O homem representado não era um nobre, seu título foi-lhe conferido pelo seu trabalho. $\mathrm{O}$ homem descrito poderia ser o que adjetivamos atualmente como o antenado, aquele que trabalha e ainda arranja tempo para se manter informado, ou, como esboçado no texto do periódico, aquele que no seu descanso, alimenta a sua alma com a investigação da verdade e da justiça. 


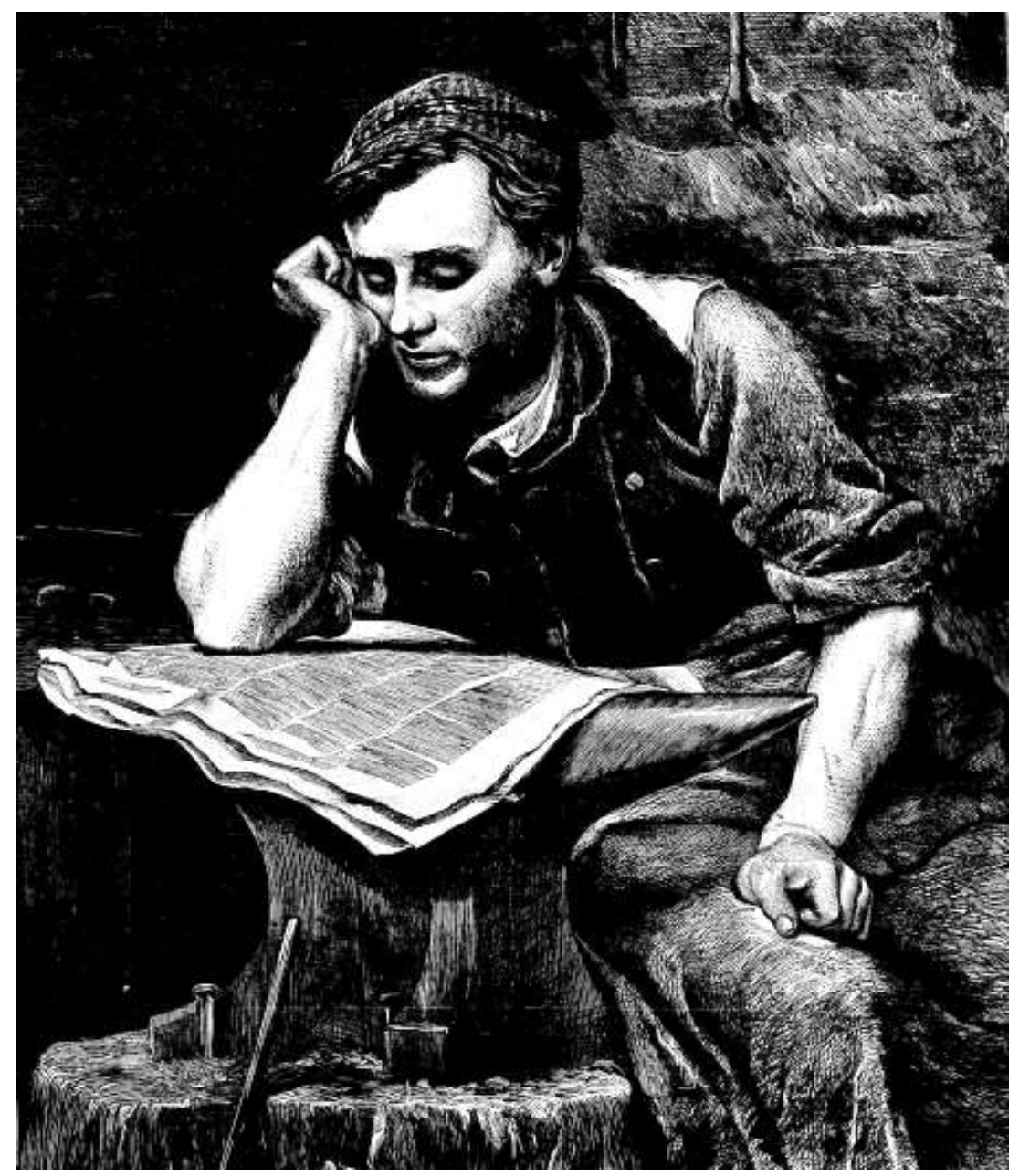

Figura 1: O tipo do homem do século XIX

Fonte: O Novo Mundo (24/10/1871)

Segundo aparece no periódico, o texto se refere à ilustração acima, que foi capa da mesma edição. Atentemo-nos para a imagem. O homem vestido simplesmente, com camisa arregaçada deixando entrever parte da musculatura torneada de seu braço - o que já evidenciaria o uso que faz destes membros - está compenetrado lendo o que parece ser um jornal. Utiliza como apoio para a sua leitura uma bigorna que, pela ampliação do espaço onde se insere a imagem referida - escuro e sem nenhuma mobília ou ornamento que o destaque - parece estar no ambiente de trabalho. Enquanto descansa de amolar ou forjar o metal na bigorna ele lê e fortifica a sua consciência. Seria este o mesmo homem que escreve para um jornal, revista ou periódico da época? Seria este o homem que frequenta as bibliotecas, clubes e sociedades literárias e culturais? Ou seria este o homem objetivado, o que era constituído, desde menino, pela imagem de que não bastava somente ganhar o pão com o seu trabalho, tinha que ainda frequentar os bancos escolares, para assim contribuir plenamente com o progresso da nação?

Maria Pallares-Burke (1998) chama atenção para o papel da imprensa no século XIX e demonstra que alguns encaminhamentos - como a volta da Corte para a metrópole e também a independência do Brasil de Portugal - proporcionaram à imprensa uma característica muito semelhante com a da imprensa iluminista europeia, e que "uma vertente do periodismo brasileiro tornará mais e mais explícito seu propósito educacional e sua fé no poder reformador da educação" (PALLARES-BURKE, 1998, p.149). A imagem, atrelada à sua descrição, pode ser considerada uma educação pelo olhar. O homem do 
século XIX tinha a instrução suficiente que lhe permitia ler e compreender o mundo, mesmo durante a pausa de um trabalho cansativo? E onde se daria essa educação mínima? Na escola primária, que, segundo explica o inspetor geral de instrução pública do Paraná, João Manoel da Cunha,

Vem do latim schola e tem sido sempre designada para mostrar: um lugar público em que se da instrução. Variadas condições exige a escola primária. Deve ser ela de fácil acesso e por isso colocada nos centros populosos. O edifício deve ser simples e modesto, porém cômodo, claro e arejado. Isolado de outras casas, arredado do tropel e labirinto dos bairros mais ativos das cidades, oferecendo as condições higiênicas e topográficas favoráveis a seu destino e à moralidade e saúde dos meninos. É necessário que as escolas tenham uma varanda (prêau) para nelas se reunirem os meninos antes de entrarem para as classes: ela serve de arena para os ensinos ginásticos nas horas dadas ao recreio. (...) Mas esse edifício carece ser decorado, não por fausto e luxo, mas para que surta o salutar efeito de atrair a mente infantil do menino e levá-la como pela mão na senda do ensinamento: e essa decoração não é ouro, o fausto da arquitetura, nem os potentos da pintura e da estatuaria. Esse ornamento de que falo são: cartas, murais, mapas, quadros, réguas, compassos, lousas, livros, compêndios, papel, tinta, lápis, bancos, carteiras, mesas que são as máquinas de centuplicar as forças da inteligência, de suavizar os processos do trabalho mental e de fazê-lo expandir-se em abençoados produtos. (O DEZENOVE DE DEZEMBRO, 17/03/1875, p.03).

Mesmo não tendo uma imagem, a descrição das condições físicas de uma escola, feita pelo inspetor, permite vislumbrarmos a estrutura pensada por ele como apropriada para a instrução. Antes de exercer a função de inspetor geral, João Manoel da Cunha havia sido professor de instrução secundária na província, com aulas de latim e francês, durante vinte e oito anos; deputado provincial em 1862 e professor de música em escola particular por ele fundada (ALMEIDA, 2001, p.13-19). Seu lado de músico aparece no relatório que faz sobre a instrução pública em dois momentos: quando escreve sobre instrução primária e quando se refere a educação secundária feminina, como abaixo:

As artes trazem consigo ideias grandes e elevadas, sentimentos nobres e puros, ensinam a julgar com tino e a falar com acerto e ordem, habituam ao sentimento do bom e do belo, e a contrair necessidades de impressões que, em vez de fazerem degenerar, fortalecem e engrandecem nossa existência. Aliviam o peso do tedio e embotam os espinhos dos árduos deveres da vida. Entre estas prendas avultam o conhecimento da música, do desenho e da dança. (O DEZENOVE DE DEZEMBRO, 24/03/1875, p.03).

É possível observarmos também na escrita do inspetor o pensamento que relaciona o ensino artístico como propulsor da moral, contra a degeneração, muito semelhante com o que André Rebouças escreveria no periódico O Novo Mundo alguns anos depois. Notamos ainda que o ensino artístico aparece como aquele que fortaleceria a existência e aliviaria os árduos deveres da vida. Sobre o ensino de música ele enfatiza que deveria começar desde as escolas primárias:

Quem não sentiu o coração repassado da mais terna melancolia ao ouvir, quando se inaugurou o mercado desta capital, os filhos da Germânia 
cantarem as saudades e as glórias de sua pátria em imponente e majestoso coro? E por que os filhos dessa terra da poesia e da música não se hão de iniciar desde a escola nas belezas de sua arte que, preparando o ouvido as regras da melodia e da harmonia, da lhe ainda a mais delicada audição para perceber as mais fugitivas nuanças no acento prosódico de todas as línguas faladas e desenvolve lhes(....) esquisito gosto para conhecer a ciência do belo, a filosofia; da arte, a famosa criação de Baumgartem - a encantar a estética. É pois para desejar que os mestres em nossas escolas saibam ao menos a música vocal para ensina-la a infância. E já que não nos é dado tê-los como na Alemanha, onde o mestre é o organista da paróquia com o socorro de magistral rabeca, levanta e guia os coros e hinos escolares, pois ao menos o nosso preceptor dirigir com entonação (ilegível) e ritmo a saudação que a esse deve levantar a Deus e o hino patriótico que deve cantar a nação no começo e fim de cada sessão. Apure-se desde a infância o ouvido e o sentimento, com ele, estou certo, será observada na música, como na poesia, sua querida irmã, as regras do reformador (ilegível) e com estas, o banimento das (ilegível) músicas dos templos do Deus sem os intrépidos ruídos que rasgam e ofendem os ouvidos, ainda menos delicados, sem despertar lá nos seios da alma o simbolismo sutil de Wagner, que, nas mais delicadas modulações, em cada nota expressa uma palavra, em cada frase um verso, e a cada verso a poesia divina que eleva o pensamento humano das regiões terrenas e ao escabelo do trono do Senhor. (O DEZENOVE DE DEZEMBRO, 24/03/1875, p.02).

Além do desenvolvimento do ouvir e do sentir, o relatório do inspetor deixa entrever a caracterização do ensino da música nas escolas como um instrumento para incutir o sentimento de nação e elevar o pensamento humano. Ele cita dois alemães: Alexander Baumgartem (1714-1762) e Wilhelm Richard Wagner (1813-1883). O primeiro viveu no século XVII, definiu o termo estética, que referencia tanto a formação do artista e do crítico, mas que, antes de tudo, se compromete "com as condições universais em que se manifesta o belo" (TOLLE, 2007, p.06). O segundo é seu contemporâneo, foi maestro, compositor, diretor de teatro (MASSIN e MASSIN, 1997) e sua obra era mencionada em alguns jornais e revistas que circularam durante o período aqui estudado, como o periódico O Novo Mundo ${ }^{14}$.

Segundo Oliver Tolle (2007), Baumgartem "compartilha com a sua época certa concepção moral da arte, que vê na poesia o medium adequado para a educação das paixões" (TOLLE, 2007, p.11) e como expressão do sensível, mas a compreensão do fenômeno artístico, para o alemão, começaria "não na expressão acabada de uma obra de arte, e sim na experiência rudimentar do belo" (Ibidem, p.112). É possível interpretarmos que João Manoel da Cunha estava propondo essa experiência para os alunos da instrução primária paranaense, o que era uma proposta até então inédita na província, que tinha a principal preocupação em conseguir que seus alunos conseguissem dar conta de, pelo menos, ler, escrever e contar nos exames finais do ensino primário. No entanto, ele não deixa de lado a necessidade de um ensino artístico na instrução primária que contemple as profissões mecânicas, citando os colégios nos Estados Unidos - esses centros de luz criadoura - e que para isso, deveria se investir, tal como lá o fazia o governo, em "grandes, custosas e complicadas oficinas, inúmeros e delicados instrumentos, indispensáveis agentes de sua aplicação, mestres de variadas aptidões" (O DEZENOVE DE DEZEMBRO, 24/03/1875, p. 03). Para ele, o aluno deveria ser preparado para lidar também com o trâmite do comércio: 


\begin{abstract}
A fonte da riqueza mais abundante de uma nação é sem dúvida o comércio, por ser ele o centro que anima e faz germinar toda a indústria e atividade humana. Para quem seriam os trabalhos do lavrador, as fadigas do industrial, e os jornais do operário, se lá não estivesse o negociante com o incessante cálculo de suas combinações, transformando em ouro o suor de um, trocando com mercadorias estranhas as produções nativas, e fazendo girar com sua incansável pena a roda da fortuna mercantil. O ensino complementar primário é pois imperfeito, se não conta em seu seio uma instituição regular, onde se cure com esmero e regularidade, de dar aos moços que se destinam ao comércio os variados e grandes preceitos que formam sua classe (ilegível). (O DEZENOVE DE DEZEMBRO, 24/03/1875, p. 03 - grifos meus).
\end{abstract}

Seguindo a escrita do inspetor, o aluno do ensino primário seria aquele que receberia uma instrução que promovesse a manutenção de alguns cargos, como o de comerciante, sem perder a cultura como um acessório, garantindo uma classificação social. Mas não é somente com a estrutura/arquitetura da escola e com o conteúdo a ser ensinado que João Manoel da Cunha se preocupou em seu relatório. Ele chama atenção para as vantagens de fazer com que os alunos praticassem exercícios físicos nas escolas primárias, "especialmente frequentadas pelos filhos do povo, a quem além de útil, será humanitário ensinar-lhes os meios de aumentarem suas forças por uma aplicação racional delas a todas as indústrias, (...)" e complementa que isso deve ser uma preocupação e um papel do educador da mocidade, que deve "conhecer esta arte e as escolas devem ter a capacidade e os instrumentos e meios necessários para que ela seja com esmero ensinada" (O DEZENOVE DE DEZEMBRO, 24/03/1875, p.02).

Interessante perceber como as ideias circulavam. O foco no periódico O Novo Mundo, do ano anterior, nos mostra que esta dupla entre o físico ("os exercícios ginásticos são parte essencial da educação dos grandes estabelecimentos") e o intelectual (teatro com Wagner, preleções públicas (conferências), "imprensa periódica barata e bibliotecas que existem em toda a parte") também aparecia como tendência em outros países (O NOVO MUNDO, 1874, p.139). O que podemos identificar ao longo do relatório do inspetor geral João Manoel da Cunha é que havia uma preocupação de que os filhos do povo, ou melhor, os alunos do século XIX, tivessem uma instrução que permitisse a inserção profissional no futuro, desenvolvendo as capacidades físicas e as habilidades para a indústria, comércio ou lavoura, mas que tivessem na arte o conhecimento suficiente que permitisse, além da modernização dos setores citados, o desenvolvimento da capacidade de expressão. Haveria alunos que se transformariam no homem do século XIX, tal como a imagem aqui anteriormente destacada, com condições ler e interpretar o que circulava em jornais do operário, revistas e periódicos da época; assim como haveria aqueles que assumiriam os cargos de chefia dentro da estrutura de governo, os que herdariam os negócios da família, os que se tornariam bacharéis, e estes não precisariam de uma imagem que os apresente como o homem do século, não precisariam de um reforço do valor de sua função.

\title{
Desenhando as últimas considerações
}

Quando Circe Bittencourt (2008) escreve sobre o livro didático e saber escolar, com recorte de 1810 a 1910, ela lança luz sobre a atuação do poder governamental e a constante presença empresarial na constituição escolar e na construção do livro utilizado nas escolas, evidenciando que o livro didático tem sua origem vinculada ao poder instituído e que desde 
a segunda metade do século XIX permanece a crença que toma o livro como instrumento que viabiliza os projetos educacionais. A autora demarca ainda que o livro didático atendia a formação do professor, era feito por mestres, homens de confiança e autores famosos, voltados para a escola de primeiras letras e ensino secundário, sendo escolhido pelos inspetores gerais e Conselho de Instrução e sua adoção era vigiada pela Igreja e pelo Estado (BITTENCOURT, 2008).

Com a lente voltada para a província do Paraná, percebemos que a princípio os inspetores gerais exerceram poder decisivo na escolha do livro didático que circularia nas aulas paranaenses, poder este que passa para as mãos do Conselho Literário em 1876. É possível identificarmos na escolha do livro didático, um conjunto de estratégias ${ }^{15}$ (como a do governo provincial, por meio dos sujeitos da inspeção, que demarcavam quais livros eram aceitos e utilizados) e táticas (como a dos autores, que lançavam mão de ações que permitiam a seleção da sua obra em detrimento de outra; e como a dos professores, que podiam algumas vezes emitir o parecer sobre a obra, antes da mesma ser distribuída para todas as escolas). O livro didático se insere nessa correlação de forças para a sua escolha e "sempre instaura uma ordem, quer seja a ordem de sua decifração, a ordem segundo a qual deve ser entendido ou a ordem determinada pela autoridade que o encomendou ou que o autorizou" (CHARTIER, 1997, p.07). A ordem dada para esta seleção no Paraná fica clara quando investigamos os livros de Abílio César Borges: o livro didático deveria ter seu conteúdo pertinente ao ensino proposto e aprovado pela Inspetoria de Instrução, entretanto, só isso não era garantia; para ter a chancela da circulação nas escolas, ele também deveria trazer benefícios para os cofres provinciais, o que seria uma contrapartida mais que sedutora.

Ao adotar o livro Desenho Linear ou Elementos de Geometria Prática Popular, de Abílio César Borges, nas escolas públicas primárias, a província do Paraná coadunou com uma perspectiva de ensino artístico com função previamente delimitada, visando a indústria, ou, nas palavras de Barbosa (1978), com um período que tomava "a Arte aplicada à indústria, vista não apenas como uma técnica mas como possuindo qualidades artísticas capazes de elevar a alma às etéreas regiões do Belo" e que deveria fazer parte dos currículos das escolas primárias e secundárias (BARBOSA, 1978, p.38).

Este reforço da aplicabilidade da Arte na vida e no futuro trabalho dos alunos paranaenses em sua fase adulta, também aparece no relatório do inspetor geral João Manoel da Cunha, cuja proposta se difere do que os outros inspetores até então vinham apontando em seus relatos na província. $\mathrm{O}$ inspetor foi um homem que transitou durante um bom tempo pela estrutura administrativa da província e, como inspetor geral, teve oportunidade de elencar o que considerava pertinente ser ensinado nas escolas paranaenses, utilizando muitas vezes o jornal O Dezenove de Dezembro, o que garantia que suas ideias circulassem não somente pelos partícipes do ensino. Desde o momento que assume a inspetoria de instrução pública ele demarca a importância da escola para o desenvolvimento do aluno e, consequentemente, da nação, como o fez em 1874: "a escola se propõe um fim mais nobre e moral. Ela se propõe, mais que tudo, a implantar a morigeração e a dignidade nas almas infantis que lhe são confiadas (...)" (O DEZENOVE DE DEZEMBRO, 05/12/1874, p.01).

Ao referenciar Baumgartem e Wagner, o inspetor João Manoel da Cunha reforça o seu lugar de conhecedor de música e poesia, mas, para além disso, deixa-nos entrever uma preocupação com a ampliação do ensino artístico na província paranaense, que não se voltasse apenas para o desenho linear e geométrico, mas que abarcasse atividades de caráter estético. Mesmo não citando de onde retira suas referências, ao ler o periódico $O$ Novo Mundo, devido à carta que André Rebouças publicou sobre o livro de Abílio, 
podemos identificar que o inspetor tem em suas proposições ideias que circulavam por esta folha. Ana Mae Barbosa (1978) demarca que O Novo Mundo contribuiu muito para a divulgação no Brasil do progresso industrial nos Estados Unidos, "atribuído à precoce iniciação da juventude americana no estudo do Desenho e à boa organização naquele país da Arte aplicada à indústria" (BARBOSA, 1978, p.39). Ao citar os colégios americanos que tomava como referência para a educação feminina, o inspetor menciona o College Vasar, que teve um grande destaque nas páginas do O Novo Mundo três meses antes (O NOVO MUNDO, 23/12/1874, p.74). É claro que não podemos afirmar que o inspetor tivesse acesso ao periódico supracitado, todavia, esta informação evidencia que ele se mantinha informado do que era considerado como modelo para o ensino artístico em outros locais.

Vasti Almeida (2001) escreve que João Manoel da Cunha realizava em sua casa pequenos concertos de música de câmara, com o quarteto formado por ele como primeiro violino, seu irmão Jacintho Manoel como segundo violino, José de Brito na viola e major Bento Antonio de Menezes no violoncelo ou piano (ALMEIDA, 2001, p.17). Já Renato Almeida (1942), ao escrever a História da Música Brasileira, aponta que João Manoel da Cunha, em suas audições, executava Haydn, Mozart e Beethoven (ALMEIDA, 1942, p.438). Em seu relatório cita Richard Wagner como exemplo do que chamou de simbolismo sutil que consegue expressar em palavras uma melodia que eleva a alma. Desde 1871 que o trabalho de Wagner é mencionado e ovacionado nas páginas de $O$ Novo Mundo: "o grande músico e favorito da corte da Baviera" (O NOVO MUNDO, 24/08/1871, p.170); aquele que "geralmente é chamado o músico do futuro tem ganho nestes últimos tempos grande prestígio no mundo artístico" (O NOVO MUNDO, 23/12/1873, p.46); “ele entende que a música não é nada se não exprime os sentimentos da letra: acrifica-a, pois, algum tanto para elevar o resto que forma ou deve formar a verdadeira ópera" (O NOVO MUNDO, 23/04/1874, p.124). Novamente o relatório de João Manoel da Cunha aponta para tendências que circulavam, porém, ao enfatizar que os alunos matriculados nas aulas públicas primárias deveriam ter o ensino de música, ele agrega esta ao que já existia como ensino artístico: o desenho. Mesmo sendo uma proposição e não uma efetivação, não deixa de ser considerado um diferencial se aplicada nas escolas primárias. Fica o convite para que futuras pesquisas procurem por pistas de ensino de música nos relatórios de professores, mesmo sem ter sido esta proposta aprovada em nenhum regulamento de instrução da província...

\section{REFERENCIAL BIBLIOGRÁFICO}

AGASSIZ, Jean Louis Rodolf, 1807-1873. Viagem ao Brasil 1865-1866/Louis e Elisabeth CaryAgassiz; tradução e notas de Edgar Sussekind de Mendonça - Brasília: Senado Federal, Conselho Editorial, 2000. 516p. - (Coleção O Brasil visto por estrangeiros)

ALMEIDA, Renato. História da Música Brasileira. 2a ed. Rio de Janeiro: F. Briguiet, 1942.

ALMEIDA, Vasti de Souza. Brazílio Itiberê da Cunha: diplomata músico. Curitiba: Editora da UFPR, 2001. 
ASCIUTTI, Monica Maria Rinaldi. Um lugar para o periódico O Novo Mundo (Nova Iorque, 1870-1879). Dissertação (Mestre em Letras). Universidade de São Paulo, 2010.

BARBOSA, Ana Mae Tavares Bastos. Arte-educação no Brasil: das origens ao modernismo. São Paulo: Perspectiva, 1978.

. Arte-educação: Conflitos/Acertos. São Paulo: Max Limonad, 1984.

- Arte-Educação Contemporânea ou Culturalista. Anais do XV Congresso Nacional da Federação de Arte-Educação do Brasil. Brasília, dez, 2006.

BARBOSA, Etienne B. L. Uma teia de ações no processo de organização da inspeção do ensino no Paraná (1854-1883). Dissertação (Mestrado em Educação), Universidade Federal do Paraná, 2012.

BATISTA, Antonio Augusto Gomes. Um objeto variável: textos, impressos e livros didáticos. In: ABREU, Márcia (org). Leitura, história e história da leitura. Campinas, São Paulo: Associação de Leitura do Brasil: Fapesp, 1999.

BITTENCOURT, Circe Maria Fernandes. Livro didático e conhecimento histórico: uma história do saber escolar. Tese de Doutorado em História. USP, 1993.

Autêntica Editora, 2008.

. Livro Didático e saber escolar (1810-1910). São Paulo:

CAMPOS, G. V. de. O literário e o não-literário nos textos e imagens do periódico ilustrado O Novo Mundo (Nova Iorque, 1870 - 1879). Dissertação (Mestrado em Teoria Literária) - Instituto de Estudos da Linguagem, Universidade Estadual de Campinas, Campinas, 2001.

CERTEAU, Michel de. A invenção do cotidiano. Artes de fazer. Petrópolis, RJ: Vozes, 1994.

CHARTIER, Roger. A História Hoje: dúvidas, desafios, propostas. Estudos Históricos, Rio de Janeiro, vol7 n. 13, 1994, p. 97-113.

Editora UNESP, São Paulo, 1997.

A aventura do livro: do leitor ao navegador.

CHERVEL, André. História das disciplinas escolares: reflexões sobre um campo de pesquisa. Teoria \& Educação, 2, 1990.

GINZBURG, Carlo. O fio e os rastros: verdadeiro, falso, fictício. Tradução de Rosa Freire d'Aguiar e Eduardo Brandão. São Paulo: Companhia das Letras, 2007.

GONDRA, José Gonçalves. SAMPAIO, Thiago. Ciência pela força? Dr. Abílio Cesar Borges e a propaganda contra o emprego da palmatória e outros meios aviltantes no ensino da mocidade (1856-1876).ActaScientiarum. Education Maringá, v. 32, n. 1, p. 75$82,2010$. 
MASSIN, Jean. MASSIN, Brigitte. História da Música Ocidental. Nova Fronteira: Rio de Janeiro, 1997.

NICOLAS, Maria. Cem Anos de Vida Parlamentar... Deputados provinciais e estaduais do Paraná. Assembleias Legislativas e Constituintes (1854-1954). Assembleia Legislativa: Curitiba, Paraná, 1954.

OSINSKI, Dulce Regina Baggio. Arte, história e ensino: uma trajetória. $2^{\mathrm{a}}$ ed. São Paulo: Cortez, 2002.

PALLARES-BURKE, Maria Lúcia. A imprensa periódica como empresa educativa no século XIX. Caderno de Pesquisa, 1998, p.144-161.

SILVA, Elza Miné da Rocha e. O Novo Mundo 1870 - 1879, Da Enunciação da Proposta às Suas Revisitações. Tese (Livre-Docência em Filologia e Língua Portuguesa) Faculdade de Filosofia, Letras e Ciências Humanas, Universidade de São Paulo, São Paulo, 1991.

SOARES, Flávia dos Santos. Por dentro da Escola Normal da Corte: programas, compêndios e professores de Matemática. In: Anais da 34 ${ }^{\mathrm{a}}$ reunião anual da ANPED, GT 19 (Educação Matemática), 2011.

THISTLEWOOD, David. A história da ideia de utilidade social na educação da arte e do design na Inglaterra. In: BARBOSA, Ana Mae. História da Arte-Educação. A experiência de Brasília. I Simpósio Internacional de História da Arte-Educação - ECA - USP. São Paulo: Max Limonad, 1986.

TOLLE, Oliver. Luz Estética: a ciência do sensivel de Baumgarten entre a arte e a iluminação. Tese (Doutorado em Filosofia). Universidade de São Paulo, 2007.

TRINCHÃO, Gláucia. O conhecimento em desenho das escolas primárias imperiais brasileiras: o livro de desenho de Abílio César Borges. História da Educação, ASPHE/FaE/UFPel, Pelotas, n²3, p.125-147, set/dez, 2007.

VALDEZ, Diane. A representação de infância nas obras pedagógicas do Dr. Abílio César Borges: o barão de Macahubas (1856-1891). Tese de Doutorado em Educação. Universidade Estadual de Campinas, 2006.

Livros de leitura seriados para a infância: fontes para a história da educação nacional (1866-1930). Linhas (Revista do Programa de Mestrado em Educação e Cultura), Florianópolis, ano 5, nº 2, p.219-241, jul. 2004.

\section{FONTES}

BCE-PR. Actas do Conselho Literário (1876-1880) - LIVRO 87.

BCE-PR. Actas do Conselho Literário (1880-1889) - LIVRO 88. 
BN. GAZETA PARANAENSE. Nota de falecimento e homenagem a João Manoel da Cunha, 02/08/1887, p.03.

BN. O NOVO MUNDO. Institutos Agrícolas, 24/10/1870, p.11.

BN. O NOVO MUNDO. Imagem. "O tipo do homem do século XIX”, 24/10/1871, capa.

BN. O NOVO MUNDO. Divertimentos Públicos. O físico e o intelectual, 23/05/1874, p.139.

BN. O NOVO MUNDO. O VassarCollege, 23/12/1874, p.74.

BN. O NOVO MUNDO. Texto escrito por André Rebouças: A Generalização do Ensino do Desenho, novembro, 1878, p.246.

BN. O NOVO MUNDO. Carta de André Rebouças sobre o livro de Abílio César Borges, junho, 1879, p.138.

BMP-PR. PROVÍNCIA DO PARANÁ, 30/01/1876 - Abílio envia 400 livros.

BMP-PR. O DEZENOVE DE DEZEMBRO. Comunicado do inspetor geral João Manoel da Cunha, 05/12/1874, p.01.

BMP-PR. O DEZENOVE DE DEZEMBRO. Relatório do inspetor geral João Manoel da Cunha, 24/03/1875, p.01-02.

BMP-PR. O DEZENOVE DE DEZEMBRO. Expediente do Secretário ao diretor geral. Envio de livro, 13/02/1879, p.03.

BMP-PR. O PARANAENSE. Menção aos acordes encontrados na música de Wagner, 05/09/1879, p.03.

BORGES, Abilio Cesar. Desenho Linear ou Elementos de Geometria Prática Popular. Livraria Mundial. $18^{a}$ edição, 1882.

DEAP-PR. Relatório de inspeção. BARROS, Bento Fernandes de. Curityba, Typ. Paranaense de Candido Martins Lopes, 1871.

\footnotetext{
${ }^{1}$ Segundo Barbosa (2012), Durante o espaço de treze anos (1858 a 1871), Bento Fernandes de Barros foi nomeado três vezes inspetor geral interino - em substituição de Joaquim Ignácio Silveira da Motta (2 meses, em 1858 e 1859) e de José Lourenço de Sá Ribas (2 meses em 1860) - e em 14 de julho de 1870 foi alçado à Inspetor Geral, exercendo a função durante sete meses. Nascido em Fortaleza, era bacharel em ciências jurídicas e sociais pela Faculdade de Direito de Olinda, Pernambuco, formado em 1853. Em sua carreira pública na província paranaense exerceu várias funções: chefe de polícia (1859), juiz de direito de Guarapuava (1871), inspetor do tesouro provincial e advogado da Câmara Municipal de Curitiba, em 1874 (NICOLAS, 1954, p.113).

"“Nascido no povoado de Macaúbas, então pertencente à pequena Vila de Rio de Contas, foi médico e "pedagogo" e um dos primeiros a se preocupar com nacionalização da produção de livros escolares destinados à instrução primária e secundária no Brasil. Proprietário de escolas, gestor da instrução pública, recorreu regularmente à imprensa nacional em defesa de suas teses e iniciativas pedagógicas. Estas são
} 
algumas possibilidades de se descrever o personagem Abílio César Borges que também se viu agraciado em vida com o título nobiliárquico de Barão de Macaúbas pelo Imperador D. Pedro II e homenageado postumamente, tendo seu nome e titulação sido adotados em diversas escolas públicas nos Estados da Bahia, Rio de Janeiro e Minas Gerais. Estados nos quais implantou seus colégios". (GONDRA E SAMPAIO, 2010, p. 75).

${ }^{3}$ No período aqui abarcado, onze inspetores/diretores gerais ficaram a frente da Inspetoria de Instrução Pública, ora como efetivos, ora como substitutos (BARBOSA, 2012).

${ }^{4}$ Gláucia Trinchão (2007) escreve que o presente livro pode ser visto como "suporte da história dessa disciplina, memória da cultura e do saber escolar. Ele permite o registro de manipulação de um saber, que neste caso é o Desenho Geométrico" (TRINCHÃO, 2007, p.131). Os livros de Leitura de Abílio César Borges também foram utilizados nas escolas paranaenses e de outras províncias no século XIX. Sobre os mesmos ver VALDEZ $(2004 ; 2006)$.

${ }^{5}$ João Manoel da Cunha nasceu em 01/02/1821, em Santana do Livramento, no Rio Grande do Sul. Estudou em Paranaguá, no Paraná, depois seguiu para São Paulo, onde cursou Direito até o $3^{\circ}$ ano. "O falecimento de seu genitor obrigou-o a abandonar o curso", tirando carta de advogado aprovisionado. (ALMEIDA, 2001, p. 13-14). Faleceu em 01/08/1887, em Curitiba, sendo homenageado nos periódicos paranaenses (GAZETA PARANAENSE, 02/08/1887).

${ }^{6}$ Entre estas negativas estava a da obra Tabuada Moderna, do professor Lindolpho Siqueira Bastos, de Morretes - a análise feita pelo Conselho concluiu "que em vista dos seus defeitos capitais, não se podia adotar nas escolas da província” (LIVRO 88, 01/10/1880).

${ }^{7}$ CERTEAU, 1994.

${ }^{8}$ GINZBURG, 2007.

${ }^{9}$ O jornal O Novo Mundo (Nova Iorque - 1870-1879) foi fundado por José Carlos Rodrigues, “jovem brasileiro residente nos Estados Unidos, era um entusiasta do progresso material e grande admirador daquele país: insistia na ideia de que o Brasil deveria seguir o modelo de desenvolvimento estadunidense" (ASCIUTTI, 2010, p.12). Silva (1991) e Campos (2001) também trabalharam com o periódico O Novo Mundo.

${ }^{10}$ Sobre a utilização e significado da palavra "disciplina" no século XIX, André Chervel (1990) escreve que esta significaria a instrução que o aluno recebe do professor, mas que, "na realidade, essa nova acepção da palavra [que antes tinha mais o sentido de disciplinar, vigiar, reprimir condutas na escola] é trazida por uma larga corrente de pensamento pedagógico que se manifesta, na segunda metade do século XIX, em estreita ligação com a renovação das finalidades do ensino secundário e do ensino primário. Ela faz par com o verbo disciplinar, e se propaga primeiro como um sinônimo de ginástica intelectual, novo conceito recentemente introduzido no debate" (CHERVEL, 1990, p.179).

${ }^{11}$ Em suas palavras: "disciplina a meu ver tão principal, como qualquer das que constituem; mais do que todas fácil de aprender, além de utilíssima, porque esclarece e dá tempera ao espírito sem fatiga-lo, enriquecendo-o com numerosíssimas ideias exatas de usual e constante aplicação prática, e despertando nos meninos a faculdade da observação, e portanto o gosto de aprender" (BORGES, 1882, p.08).

12 Paulino Martins Pacheco era professor da Escola Normal de Niterói, no Rio de Janeiro, "engenheiro, foi delegado de Instrução Pública, diretor dos cursos mantidos pela Sociedade Auxiliadora da Indústria Nacional, professor do Colégio Pedro II e do Instituto Comercial" (SOARES, 2011, p.08).

${ }^{13}$ Em várias fontes encontramos o envio de livros de Abílio César Borges para a província do Paraná, como doação, como aparece no jornal Província do Paraná, em 1876, o envio de 400 livros.

${ }^{14}$ A menção a Richard Wagner também aparece no jornal O Paranaense, em 1879.

${ }^{15}$ Estratégias e táticas entendidas em consonância com o trabalho de Michel de Certeau (1994).

Recebido: nov-13 Aprovado: abr-14 